\begin{tabular}{|l|l|l|}
\hline \multicolumn{2}{|c|}{ PublisherInfo } \\
\hline \hline PublisherName & $:$ & BioMed Central \\
\hline \hline PublisherLocation & $:$ & London \\
\hline \hline PublisherImprintName & $:$ & BioMed Central \\
\hline \hline
\end{tabular}

\title{
A primitive energy pathway in fungus
}

\begin{tabular}{|l|l|l||}
\hline \multicolumn{2}{|c|}{ ArticleInfo } \\
\hline \hline ArticleID & $:$ & 5082 \\
\hline \hline ArticleDOI & $:$ & $10.1186 /$ gb-spotlight-20050429-02 \\
\hline \hline ArticleCitationID & $:$ & spotlight-20050429-02 \\
\hline \hline ArticleSequenceNumber & $:$ & 58 \\
\hline \hline ArticleCategory & $:$ & Research news \\
\hline ArticleFirstPage & $:$ & 1 \\
\hline \hline ArticleLastPage & $:$ & 3 \\
\hline \hline & & RegistrationDate : 2005-4-29 \\
\hline ArticleHistory & $:$ & OnlineDate \\
\hline \hline ArticleCopyright & $:$ & BioMed Central Ltd2005-4-29 \\
\hline \hline ArticleGrants & $:$ & \\
\hline \hline ArticleContext & $:$ & 130596611 \\
\hline \hline
\end{tabular}




\section{Charles Q Choi}

Email: cqchoi@nasw.org

Some 20 fungi species may possess an energy-generating proton pump never before seen outside prokaryotes, scientists report in this week's PNAS. The investigators suggest the system could be widely spread among lower eukaryotes.

"The most surprising thing for me is that the fungi have kept this primitive energy pathway even though they possess normal respiration," said coauthor Leonid Brown, of the University of Guelph in Canada.

Eukaryotes are classically thought to create proton gradients for energy via respiration and chlorophyll. Over the last 30 years, scientists have found that archaea and eubacteria possess another form of photosynthesis, where bacteriorhodopsin-like membrane proteins drive light-driven translocation of protons. Homologous rhodopsins examined in eukaryotes until now apparently only had photosensory functions.

In the current study, Brown and colleagues analyzed the fungus Leptosphaeria maculans opsin gene and found a high degree of homology with bacteriorhodopsin. After expressing the opsin in membranes of the yeast Pichia pastoris, time-resolved laser spectroscopy in the visible range revealed its photocycle turnover was very fast, at a few tens of milliseconds.

"As a rule, fast photocycle turnover is what you see for efficient proton transport, while slow photocycles are linked to photosensors," Brown told The Scientist.

To characterize the opsin, Brown and colleagues reconstituted it into proteoliposomes. Time-resolved spectroscopic analysis revealed that when investigators immersed these proteoliposomes in deuterated water, the opsin photocycle slowed down compared to normal water, implying proton transfer steps which the higher mass of the deuterons would delay. Rapid-scan Fourier transform infrared difference spectroscopy on proteoliposomes confirmed the opsin photocycle was bacteriorhodopsin-like, with all major retinal and carboxylic acid vibrational bonds matching closely.

To test whether light-driven proton pumping occurs, Brown and colleagues illuminated proteoliposomes and found acidification inside them and alkalinization of their surrounding medium, which fully reversed in the dark. Addition of the proton uncoupler CCCP abolished nearly all these light-induced $\mathrm{pH}$ changes. The researchers estimate each opsin molecule pumps one to 10 protons per second under nearly saturating light conditions.

More than 20 bacteriorhodopsin-like proteins are known in fungi so far. Brown speculated that $L$. maculans, a parasite of canola, might use this pathway to revive itself from dormancy.

Aside from energy, light-driven protons might acidify compartments in the cell. "It could be doing this to control growth patterns, for instance," noted Thomas Ebrey at the University of Washington, who did not participate in this study. Future experiments could knock out opsin and analyze what happens in a variety of environmental conditions, Ebrey told The Scientist. Brown plans to collaborate on genetic studies with Barbara Howlett at the University of Melbourne in Australia and colleagues, who first discovered L. maculans' opsin gene. 
Immunological experiments could determine where opsin is localized in L. maculans, said Shil DasSarma of the University of Maryland, who did not participate in this study. "If they are in the mitochondria, they are likely to be used for generating ATP," he told The Scientist. "This would suggest that organisms that were the precursors to the mitochondria may have previously developed the capability for phototropic growth."

Brown plans to compare the primary structures of several rhodopsins to pinpoint residues that, upon mutation, render L. maculans opsin more like photosensory rhodopsins. "As for 3D structures, we will try to crystallize some of the rhodopsins, but we'll need to optimize procedures for higher yields," he said. "The good thing about fungal rhodopsins is we have good X-ray structures for bacteriorhodopsins, so we can make good 3D models based on those templates and plan mutagenesis that way."

A potential application of these fungal rhodopsins is rendering neurons sensitive to light.

"Leptosphaeria rhodopsin is an ideal candidate for this, as it is eukaryotic, so it will be stable in neurons, and can change the membrane potential quickly by transporting protons," Brown said.

\section{References}

1. S.A. Waschuk et al., "Leptosphaeria rhodopsin: Bacteriorhodopsin-like proton pump from a eukaryote," PNAS, April 25, 2005., [http://www.pnas.org]

2. Leonid Brown, [http://www.uoguelph.ca/ lebrown/]

3. L. Hrastar, "Opsin mediates circadian clock," The Scientist, January 28, 2005., [http://www.thescientist.com/news/20050128/02]

4. D. Oesterhelt, W. Stoeckenius, "Functions of a new photoreceptor membrane," PNAS, 70:2853-7, October 1973.

5. O. Beja et al., "Proteorhodopsin phototrophy in the ocean," Nature, 411:786-9, June 14, 2001.

6. Thomas Ebrey, [http://protist.biology.washington.edu/bio2/people/bio.html?parecID=91]

7. A. Idnurm, B.J. Howlett, "Characterization of an opsin gene from the ascomycete Leptosphaeria maculans," Genome,44:167-71, April 2001.

8. Shiladitya DasSarma, [http://zdna2.umbi.umd.edu/ dassarma] 